\title{
The burden of lung disease in Europe: data from the first European White Book
}

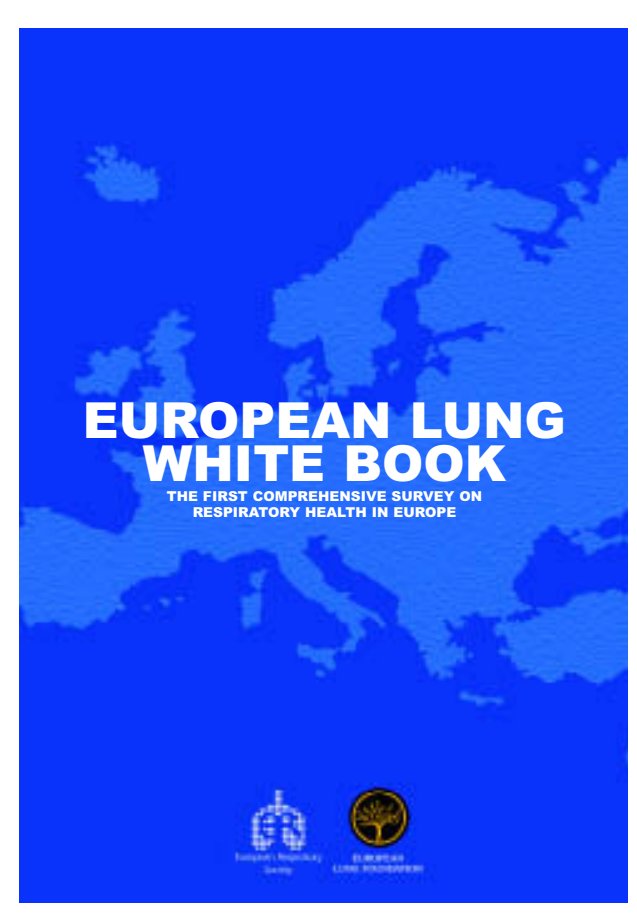

At the beginning of a new millennium, respiratory disorders are the leading cause of death worldwide, and a further increase in mortality is expected in the future.

In this context, the European Respiratory Society (ERS), the leading professional association in Europe for respiratory medicine, and the European Lung Foundation (ELF), its public voice, considered it essential to publish a document providing an overview of the ever-increasing impact lung disease is having on the lives of all Europeans.

The European Lung White Book, which is the first comprehensive survey of respiratory health in Europe, was launched to the members of the European Parliament in Brussels/ Belgium on 25 November, 2003. The publica- tion of this report would not have been possible without the help of a large number of experts from all over Europe; more than 50 contributors (section editors, authors and reviewers) participated in writing this publication. The data presented in the European Lung White Book were collated from several sources, including the European Community, the World Health Organization (WHO), the Organization for Economic Cooperation and Development $(\mathrm{OECD})$, and from national statistics collected with the help of ERS national delegates.

In Europe, respiratory diseases rank second (after cardiovascular diseases) in terms of mortality, incidence, prevalence and costs. In some countries (e.g. the UK), they are already the leading killer. Lung cancer, pneumonia and chronic obstructive pulmonary disease (COPD) are the main respiratory causes of death in Western Europe, as well as in Central and Eastern Europe. In both parts of Europe, lung cancer ranked third in 1990 (after ischaemic heart and cerebrovascular diseases), followed by pneumonia in the fourth position, and COPD in positions five and eight, respectively. It is already estimated that in 2010, COPD will have risen to fourth place.

Overall, there is considerable variation among European countries in the age-standardised death rates per 100,000 population from respiratory diseases, with a broad range between 30 and 165, a European average of 65 and an European Union (EU) average of approximately 57. Ireland and the UK are among the leading countries with 120 and 105 deaths, respectively, whereas other Western, as well as most Central European countries, remain below the average. The reasons for these discrepancies are not clear and should certainly become an area of future research.
R. Loddenkemper ${ }^{1}$

G.J. Gibson ${ }^{2}$

Y. Sibille ${ }^{3}$

${ }^{1}$ Chief Editor, European Lung White Book

${ }^{2}$ President 2002-2003, European Respiratory Society

${ }^{3}$ Chair, European Lung

Foundation

\section{Correspondence:}

R. Loddenkemper

Lungenklinik Heckeshorn

Zum Heckeshorn 33

14109 Berlin

Germany

Fax: 493080022286

E-mail:

loddheck@zedat.fu-berlin.de 
"Respiratory disorders are the leading cause of death worldmortality is expected in the future." wide and a further increase in

Respiratory disorders have a considerable medical and socioeconomic impact in Europe. The European Lung White Book describes the most important respiratory diseases and provides details on the epidemiology (mortality, prevalence, incidence), aetiology (environmental, occupational, genetic and other causes), means of prevention and other measures to help fight respiratory diseases. For each type of disease, figures have been included, whenever available, regarding the current financial burden (costs of treatment, lost working days), the prediction of the situation in $5 \mathrm{yrs}$ time and the most urgent research needs. In general, a wide variation exists in incidence, prevalence, mortality and costs of respiratory diseases among the different European countries. These variations can be explained only partly, since there are sometimes considerable differences even between countries in the same region.

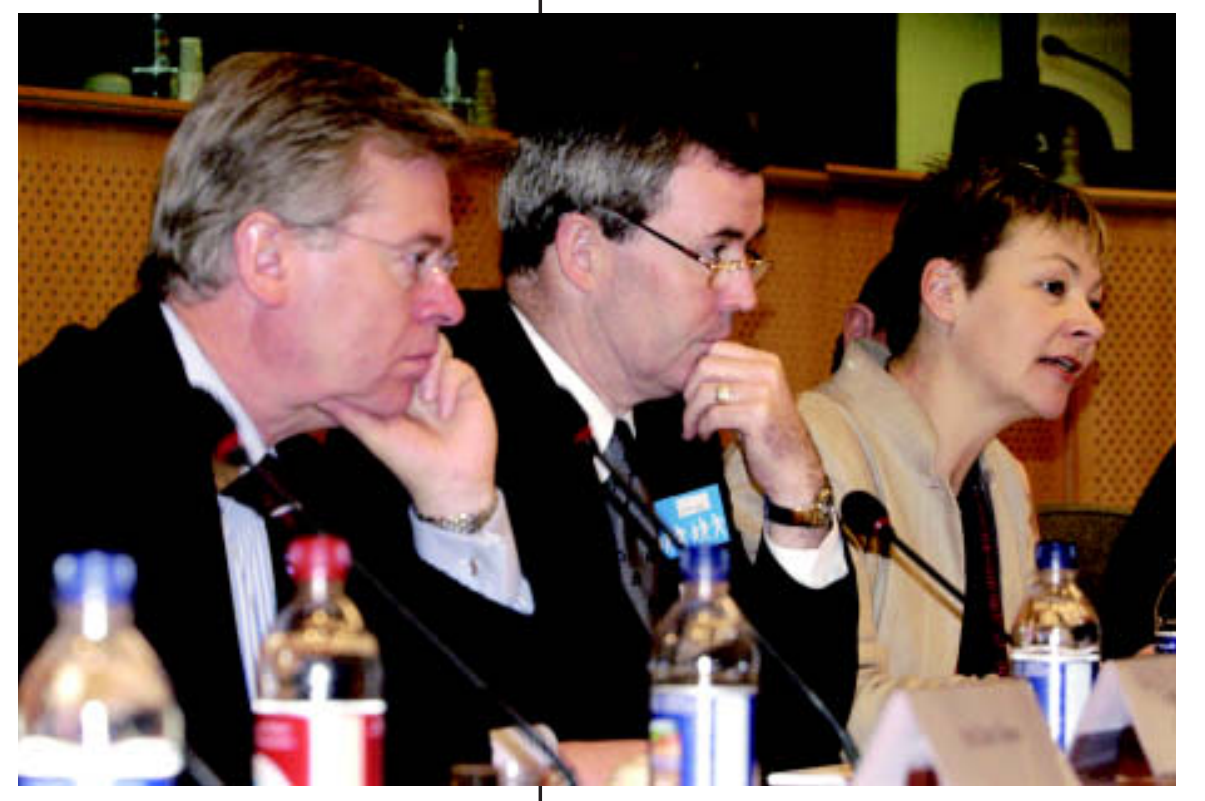

Lung cancer is predicted to remain the number three killer in Western as well as in Eastern Europe. A considerable rise in females has been observed in all regions and continues in almost all European countries.

COPD, which is also mainly related to smoking, is predicted to increase as a cause of death directly following lung cancer. The COPD mortality rates in various European countries range from $<25$ to $>75$ per 100,000 inhabitants, and its prevalence from $<2,000$ to $>10,000$ per 100,000 inhabitants.
Pneumonia will also remain an important cause of death in Europe. The current mortality from pneumonia ranges from $<15$ to $>45$ per 100,000, and its incidence from $<250$ to $>1,000$ per 100,000 inhabitants.

Asthma rates have increased continuously during recent decades. It is now the most frequent chronic disease in children, its prevalence varies from $<1 \%$ to $>15 \%$. In adults, prevalence ranges from $<5 \%$ to $>10 \%$, with a wide range of variation of reported mortality rates.

Epidemiologic data for tuberculosis(TB) are the most complete throughout Europe, due to a central surveillance system developed for all European countries. While the incidence and mortality rates of TB in Western and Central Europe are stable or declining, both have increased considerably in Eastern Europe during the last decade, due to a deterioration of health systems.

In addition to these five major disorders, data on other important respiratory diseases, such as sleep-related diseases, are also available for some Western European countries, and show a wide range of variation from $<1,000$ to $>2,000$ per 100,000 inhabitants. Data on interstitial lung diseases are scarce but likewise vary considerably regarding incidence and prevalence.

Other important and frequent respiratory diseases not covered by this first edition of the European Lung White Book, include pleural disorders and pulmonaryvascular diseases such as pulmonary embolism.

Cystic fibrosis (CF) is the most significant hereditary respiratory disease. CF also shows considerable variation in incidence between $<5$ and $>10$ per 100,000 population. With improved treatment and longer survival, patients with CF are increasingly cared for in adult as well as paediatric respiratory departments.

Occupational lung diseases are another area of interest in which epidemiological data have been accumulated. Compensated occupational lung diseases represent a high proportion of all occupational diseases, e.g. $3 \%$ in Germany.

The total financial burden of lung disease in Europe amounts to nearly $€ 102$ billion. COPD contributes almost one half of this figure, 
followed by asthma, pneumonia, lung cancer and TB. This includes direct and indirect costs of these diseases: inpatient care (17.5\%); ambulatory care (8.9\%); drug supply (6.6\%): mortality and rehabilitation (19.6\%); and lost working days $(47.4 \%)$.

The annual number of hospital days due to respiratory diseases, surprisingly, is higher in EU countries than in Central and Eastern Europe.

Concerning teaching and training in respiratory diseases, there are currently huge differences in the representation of pneumology at the university level in various European countries. Nearly one half of all European countries do not reach US standards. The negative implications of this situation for teaching and research are obvious.

Similar differences in the number of chest physicians per 100,000 inhabitants can be observed throughout Europe, butspecialised care for patients with lung diseases is organised in different ways, making comparisons very difficult.

As EU Commissioner David Byrne states in his foreword to the European Lung White Book, "Efforts must concentrate on the prevention of respiratory disease and on the improvement of patient care. The current situation in Europe not only calls for a clean environment, free of tobacco smoke and other pollutants, but also for an expansion of the means dedicated to scientific research into the treatment of lung disease".

The former Director-General of the World Health Organization in her foreword welcomes "the publication of the first European Lung White Book, as the facts and figures on tobacco-related respiratory disease highlighted in this report provide a foundation for action. This initiative of the European Respiratory Society and the European Lung Foundation shows the need for concerted action in Europe to stem the predicted expansion of respiratory disease".

Meanwhile, the European Lung White Book has been well received in the respiratory world and outside. Its smaller version, Lung Health in Europe - Facts \& Figures has been translated into eight European languages up to now (Danish, Dutch, German, French, Italian, Polish, Russian and Spanish). This widespread distribution will inform the public, including journalists and politicians, as well as the medical world, on the importance and burden of respiratory diseases. Thus, it will hopefully induce the development of a coherent European strategy for the prevention and treatment of lung diseases.

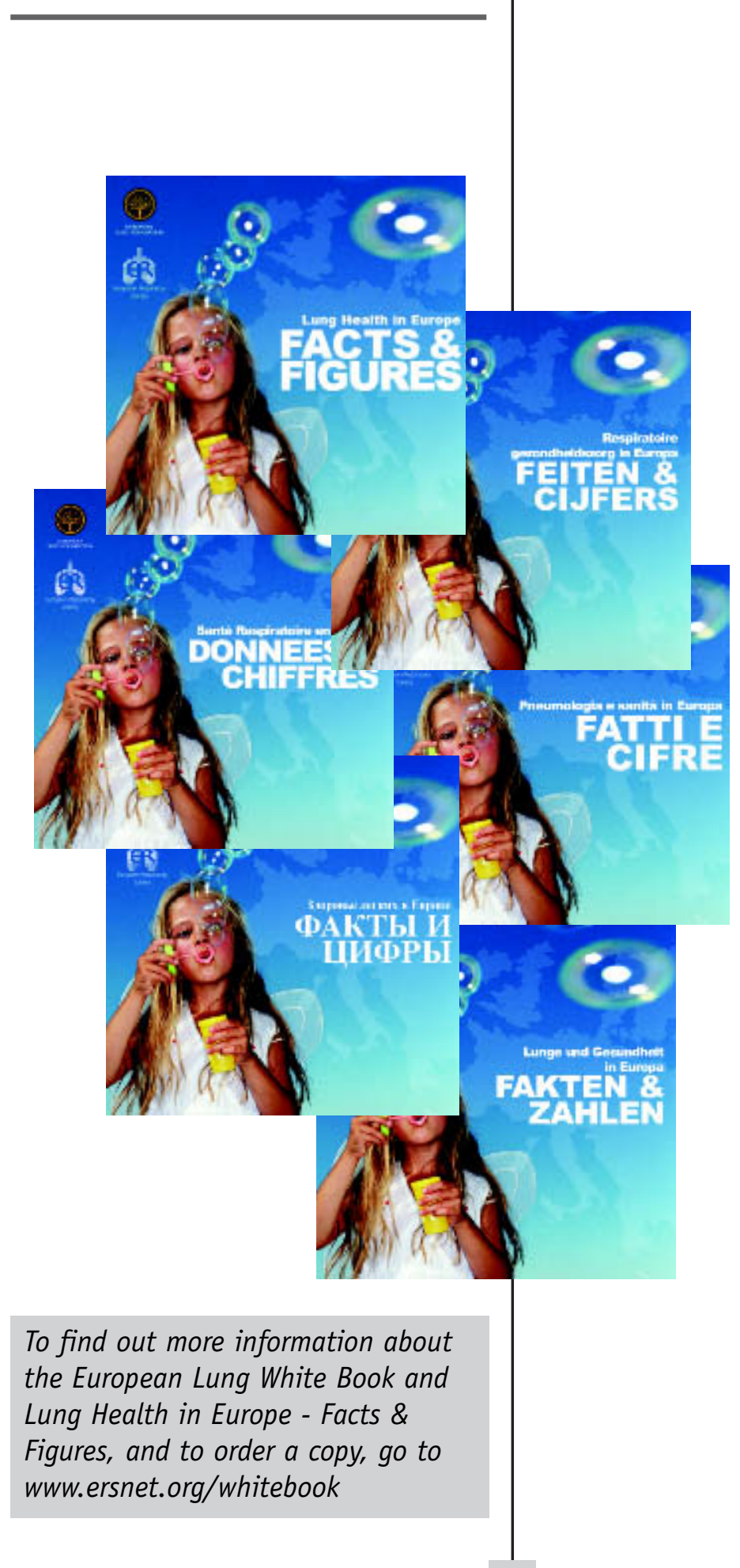

"The total financial burden of lung disease in Europe amounts to nearly $€ 102$ billion." 